\title{
Tissue plasminogen activator (tPA) attenuates propofol-induced apoptosis in developing hippocampal neurons
}

\author{
Chao Liang ${ }^{*}$, Ming Ding, Fang Du, Jing Cang and Zhanggang Xue
}

\begin{abstract}
Background: We investigated the effect of propofol on the tissue plasminogen activator (tPA) release in developing hippocampal neurons, and explored the effects of exogenous tPA on the propofol-induced neuron apoptosis.

Methods: Primary hippocampal neurons isolated from neonatal Sprague-Dawley rats were exposed to propofol (20, 50, and $100 \mu \mathrm{M}$ ) for $6 \mathrm{~h}$ either one time or three times. Finally, neurons were pretreated with exogenous tPA ( $5 \mu \mathrm{g} /$ $\mathrm{ml})$, followed by propofol exposure (100 $\mu \mathrm{M}, 6 \mathrm{~h})$. The neuron apoptosis was detected by terminal transferase deoxyuridine triphosphate-biotin nick-end labeling (TUNEL) and the protein expression of cleaved caspase-3 (Cl-Csp3) was analyzed by western blot, the tPA in media was tested by enzyme-linked immunosorbent assay.
\end{abstract}

Results: Propofol exposure significantly increased the number of TUNEL-positive neurons and Cl-Csp3 expression in developing hippocampal neurons. Propofol decreased tPA level in the media of developing hippocampal neurons. The neuron appotosis induced by propofol was attenuated by pretreatment of tPA.

Conclusion: Propofol exposure decreased tPA release in developing hippocampal neurons. The addition of tPA could partially reverse the apoptotic effect of propofol.

Keywords: Tissue plasminogen activator, Propofol, Apoptosis, Developing neurons

\section{Background}

Propofol administered during synaptogenesis can produce long-term neurobehavioral and functional deficits in animals (Creeley et al. 2013; Cattano et al. 2008; Yu et al. 2013; Li et al. 2014; Xiong et al. 2014), since the developing brain is more vulnerable to anesthetic-induced neurotoxicity (Cattano et al. 2008; Jevtovic-Todorovic et al. 2003; Fredriksson et al. 2007; Ikonomidou et al. 1999). It has been demonstrated recently that proBDNF-p75NTR signaling pathway is the key player of propofol and isoflurane-induced neurotoxicity (Head et al. 2009; Lemkuil et al. 2011; Pearn et al. 2012).

The brain-derived neurotrophic factor (BDNF) is stored as a proneurotrophin (proBDNF) within synaptic vesicles and is proteolytically cleaved to mature BDNF

*Correspondence: superwm226@aliyun.com Department of Anesthesiology, Zhongshan Hospital, Fudan University, Fenglin Road 180, Shanghai 200032, China
(mBDNF) in the synaptic cleft by plasmin (Lee et al. 2001; Keifer et al. 2009; Lu et al. 2006). The mBDNF bind with the receptor kinase $B$ and leads to neurite outgrowth and synapse stabilization and maturation (Lee et al. 2001; Keifer et al. 2009; Lu et al. 2005).While the proBDNF binds to the p75 neurotrophin receptor $\left(\mathrm{p} 75^{\mathrm{NTR}}\right)$ and initiates cellular processes that inhibit axonal elongation and cause growth cone collapse and apoptosis (Huettner and Baughman 1986). The number of plasmin in the synaptic cleft is mainly depending on the tissue plasminogen activator (tPA), which convert the plasminogen into plas$\mathrm{min}$. When the tPA is decreased, the convertion of plasminogen into plasmin may be blunted, and the number of proBDNF is increased, which then leads to inhibition of axonal elongation, growth cone collapse, and apoptosis.

The release of tPA from presynaptic vesicles is activity-dependent (Lemkuil et al. 2011), and it is therefore possible that anesthetics might suppress neuronal activity, reduce tPA release which finally results in the 
proBDNF-mediated neuron growth inhibition pathway dominant, leading to the final neuronal apoptosis. However, it is still unknown that the direct effect of propofol on the release of tPA in developing neurons, and more importantly, whether the addition of exogenous tPA could reverse the propofol induced neurotoxicity has not been investigated.

We examined whether propofol decreases tPA release, which leads to decrease proBDNF, in hippocampal neurons. In addition, we examined whether the addition of exogenous tPA attenuates the propopol-induced apoptosis in hippocampal neurons.

\section{Methods}

The experimental protocols were approved by the animal experimental ethics committee of Zhongshan Hospital, Fudan University. All experimental procedures were performed in accordance with the Guidelines for the Care and Use of Experimental Animals. Hippocampal neurons of neonatal Sprague-Dawley rats were isolated by using the method described previously. Neurons were isolated from the postnatal day 1 or 2 pups and grown in culture for 4-6 days in vitro. Neurons were cultured in media (Neuobasal A) supplemented with $250 \mathrm{mM}$ GLUTMax1 (Santa Cruz, CA), B27 (2 \%), and penicillin/streptomycin $(1 \%)$. Poly-D-lysine/laminin $\left(2 \mathrm{~g} / \mathrm{cm}^{2}\right)$ coated 48 -well plates were used to culture neurons at $37{ }^{\circ} \mathrm{C}$ in $5 \% \mathrm{CO}_{2}$ before experiments.

\section{Cell culture and treatment}

The cultures were placed within an incubator (a gas mixture of $5 \% \mathrm{CO}_{2}, 21 \% \mathrm{O}_{2}$, balance nitrogen at a flow rate of $2 \mathrm{l} /$ min, $\left.37^{\circ} \mathrm{C}\right)$ and exposed to propofol $(20,50$, and $100 \mu \mathrm{M})$ for $6 \mathrm{~h}$ either one time or three times (once per day for 3 consecutive days). In the multiple exposure groups, the neurons were rinsed with PBS for one time after each exposure, and placed in fresh media overnight. Finally, neurons were pretreated by recombinant human tPA (Santa Cruz, CA) at different concentration $(0.05-5 \mu \mathrm{g} / \mathrm{ml})$ for $15 \mathrm{~min}$, followed by propofol $100 \mu \mathrm{M}$ exposure for $6 \mathrm{~h}$. After respective treatments, the neurons were harvested and subjected to the following measurements.

\section{TUNEL staining}

After each treatment, DNA fragmentation was detected for apoptotic neurons by using the fluorometric TUNEL system (Roche Nutley, NJ) According to the manufacturer's instructions, neurons were fixed in $4 \%$ paraformaldehyde in PBS at room temperature for $20 \mathrm{~min}$, incubated with fluorescein-conjugated TdT enzyme at $37{ }^{\circ} \mathrm{C}$ for $1 \mathrm{~h}$ in humidifying chamber, and then mounted with DAPI (4',6'-diamidino-2-phenylindole) for nuclear counter staining. Both TUNEL-and DAPI-positive neurons were counted by using a Nikon Eclipse 80i fluorescence microscope (Nikon, Tokyo, Japan). Apoptosis rate was quantified by determining the ratio of TUNEL-positive nuclei to total cell nuclei.

\section{TPA ELISA}

In brief, after treatment by propofol, media from neurons were frozen at $-80{ }^{\circ} \mathrm{C}$ before preforming enzyme-linked immunosorbent assay (ELISA) (Invitrogen, Carlsbad, CA). A 48-well plate was precoated with biotinylated plasminogen activator inhibitor-1 for $30 \mathrm{~min}$, washed three times. The tPA standard $(0.05-10 \mathrm{ng} / \mathrm{ml})$ and tested samples were added to the plate for $30 \mathrm{~min}$. After incubated with anti-tPA primary antibody and anti-rabbit horseradish peroxidase-conjugated secondary antibody for $30 \mathrm{~min}$, respectively, the tetramethylbenzidine substrate was added, and the reaction was quenched $10 \mathrm{~min}$ later by $1 \mathrm{M} \mathrm{H}_{2} \mathrm{SO}_{4}$ and read at $450 \mathrm{~nm}$ on a spectrophotometer (TECAN Infinite M200, San Jose, CA).

\section{Western blot}

Briefly, after respective treatments, neurons were lysed and $15 \mu \mathrm{g}$ of proteins were boiled in a sample buffer (50 mM Tris- $\mathrm{HCl} \mathrm{pH} \mathrm{7.5,} 150 \mathrm{mM} \mathrm{NaCl}, 1 \%$ SDS, $100 \mathrm{mg} / \mathrm{mL}$ PMSF) and then separated on $15 \%$ SDSPAGE gels. The separated proteins were transferred to a nitrocellurose membranes (CNI, Canada), which was subsequently blocked in Tris-buffered saline-Tween 20 (TBST) containing $5 \%(\mathrm{w} / \mathrm{v})$ nonfat dried milk for $1 \mathrm{~h}$ at room temperature. The membrane was then incubated with appropriate concentration of primary antibody of Cl-Csp3 (1:1000, Vector Laboratories, Burlingame, CA) at $4{ }^{\circ} \mathrm{C}$ overnight. The membrane was washed and subsequently probed with horseradish per-oxidase-conjugated secondary antibody (1:2000, Sigma-Aldrich, St. Louis, MO). Blots were finally developed with a chemiluminescent HRP substrate kit (Sigma-Aldrich, St. Louis, $\mathrm{MO}, \mathrm{USA}$ ) and all protein bands were quantitated with a ImageJ version 1.38 (NIH, Bethesda, MD).

\section{Statistical analysis}

SPSS16.0 software was used to perform statistical analyses of the data. Statistics were performed using one way ANOVA and Student's $t$ test. All results are expressed as the mean $\pm \mathrm{SD}$, and $P<0.05$ was considered statistically significant.

\section{Results}

\section{The effects of propofol on neuron apoptosis}

The neurons were exposed one and three times to $6 \mathrm{~h}$ of 20,50 , and $100 \mu \mathrm{M}$ propofol. The number of TUNELpositive neurons in propofol-treated group was significantly increased when compared with these of control 
group $(P<0.05)$, following one exposure to 50 and $100 \mu \mathrm{M}$ propofol but not after a single exposure to $20 \mu \mathrm{M}$ propofol $(P<0.05)$ (Fig. 1a). The number of TUNELpositive neurons was significantly increased in all propofol-treated groups after three exposures to propofol $(P<0.05)$ (Fig. 1a). Consistently, the protein expression levels of the apoptosis executor cleaved caspase-3 $(\mathrm{Cl}-$ Csp3) were also significantly increased by propofol exposure $(P<0.05)$ (Fig. 1b).

\section{The effects of propofol on tPA release}

The neurons were exposed one and three times to $6 \mathrm{~h}$ of 20,50, and $100 \mu \mathrm{M}$ propofol. The tPA in the media was tested by ELISA. Compared with the control group, neurons exposed to propofol had less tPA in the media $(P<0.05)$ (Fig. 2).

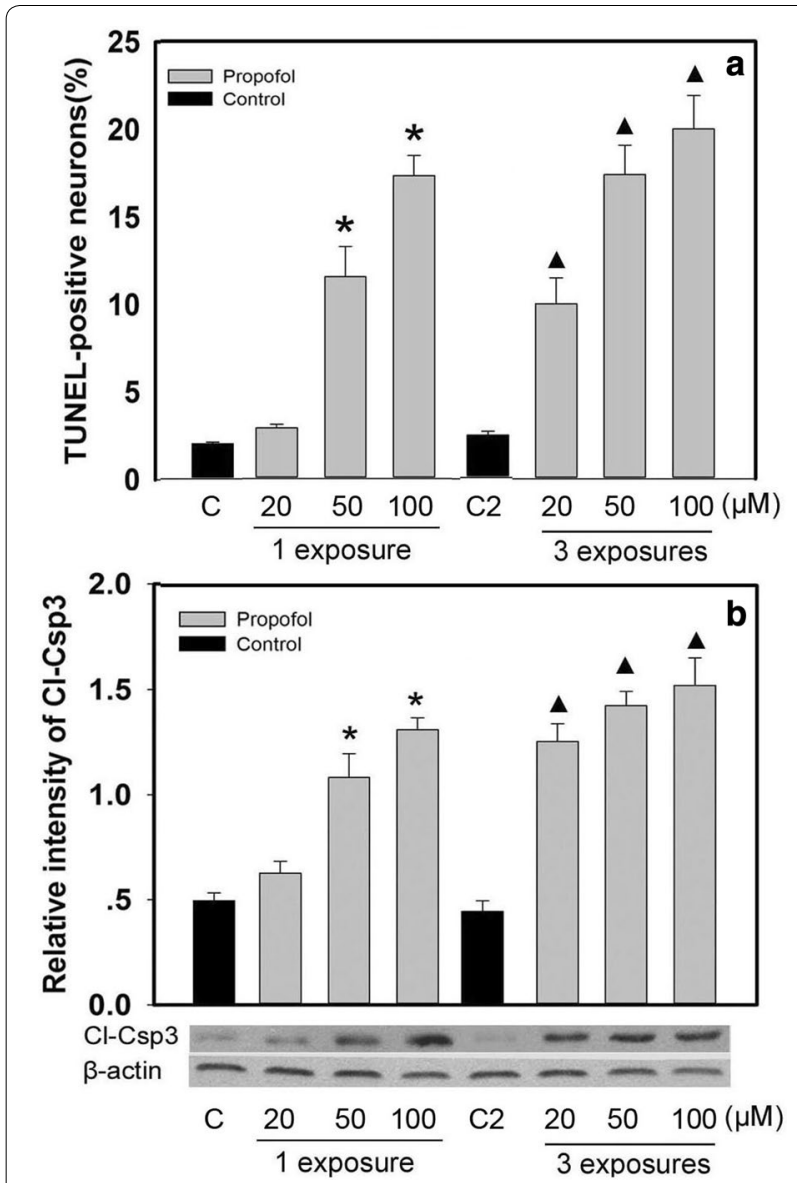

Fig. 1 Propofol induces appotosis in cultured developing hippocampal neurons. The neurons were exposed one or three times to $6 \mathrm{~h}$ of 20, 50, and $100 \mu \mathrm{M}$ propofol. After treatments, the TUNEL-positive neurons and the protein expression of $\mathrm{Cl}-\mathrm{Csp} 3$ were analyzed by TUNEL staining (a) and western blot $(\mathbf{b})$, respectively. Densitometric analysis of $\mathrm{Cl}-\mathrm{Csp} 3$ protein was performed after normalization with $\beta$-actin (b). ${ }^{*}, \mathbf{\Delta} P<0.05$ vs $C 1$ or C2. C1 control group of single exposure to propofol, C2 control group of multiple exposure to propofol

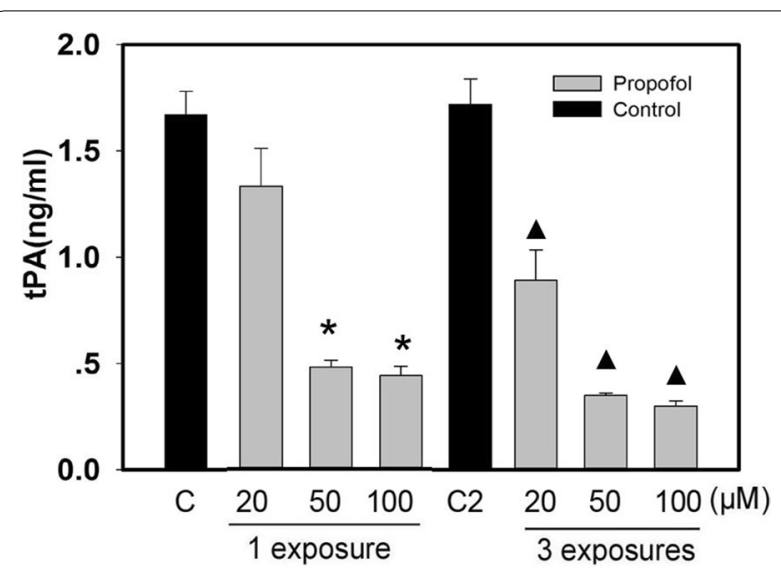

Fig. 2 The effects of propofol on tPA release

The effects of tPA addition on propofol-induced appotosis The neurons were pretreated with increasing doses of tPA $(0.05-5 \mu \mathrm{g} / \mathrm{ml})$ before exposed one time to $6 \mathrm{~h}$ of $100 \mu \mathrm{M}$ propofol. Increasing doses of tPA decreased propofolinduced apoptosis rate and Cl-Csp3 expression with a maximum decrease at $5 \mu \mathrm{g} / \mathrm{ml}(P<0.05)($ Fig. 3a, b).

\section{Discussion}

The data from the present study indicated that propofol could induce apoptosis in cultured developing hippocampal neurons, which are consistent with the findings from the previous studies (Yu et al. 2013; Pearn et al. 2012; Liu et al. 2014; Twaroski et al. 2014). Importantly, propofol exposure decreases tPA release, and the administration of exogenous tPA attenuates propofol-induced neuron apoptosis.

The new neurons from postnatal hippocampus play an important role in cognitive processes such as learning and memory. It has been reported that anesthetics lead to neurodegeneration during synaptogenesis, which is on the postnatal day 5-7 (Jevtovic-Todorovic et al. 2003). Therefore, in the present study, the isolated hippocampal neurons (postnatal day 1 or 2 pups of rats) were cultured for 4-6 days in vitro, and then undergoing respective treatments. The estimated brain concentrations of propofol in humans during the induction and maintenance of general anesthesia ranges from 22 to $112 \mu \mathrm{M}$ (Vutskits et al. 2005; Chung et al. 2013; Ludbrook et al. 2002; Costela et al. 1996), and the blood concentration of propofol for the induction of anesthesia and maintenance typically ranges from about 5 to $60 \mu \mathrm{M}$ in children (Viviand et al. 2003; Varveris and Morton 2002; Hume-Smith et al. 2008).Based on these findings, the propofol concentrations used in our study were 20,50 and $100 \mu \mathrm{M}$, and the neuron apoptosis was prominent at propofol $50 \mu \mathrm{M}$, which seems clinically significant. In addition, given 


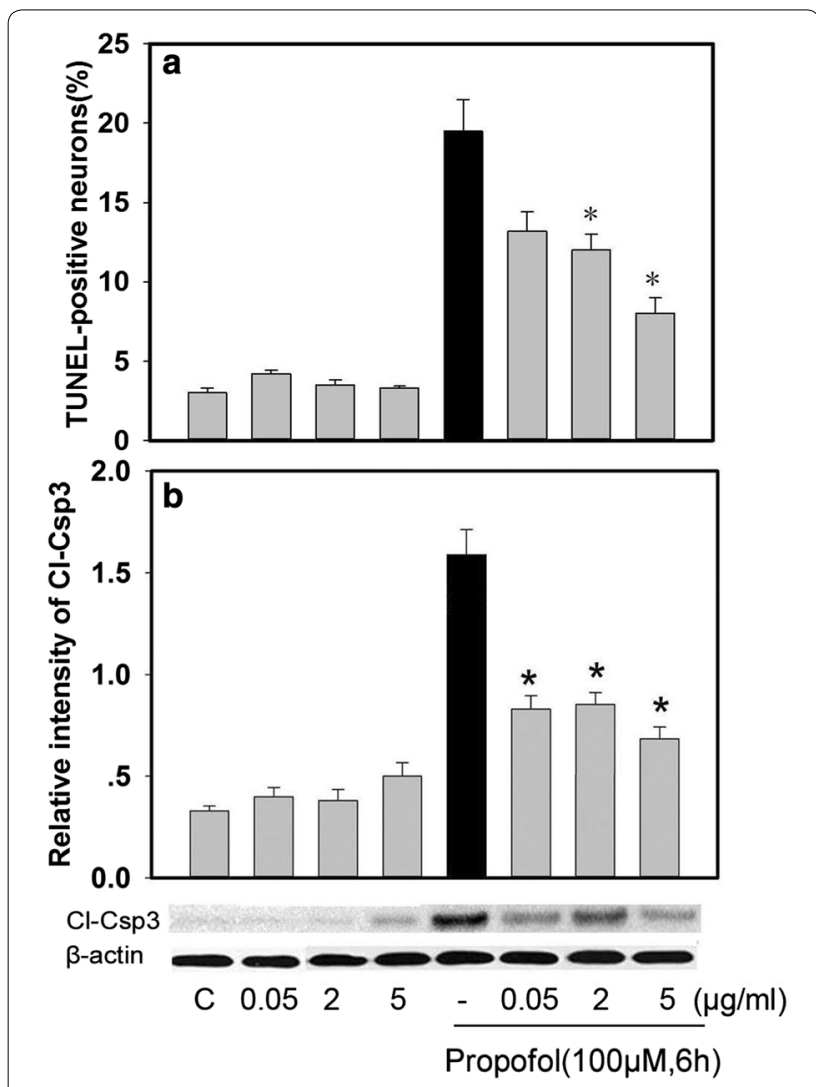

Fig. 3 tPA addition attenuates appotosis induced by propofol in cultured developing hippocampal neurons. The neurons were pretreated with increasing doses of tPA $(0.05$ to $5 \mu \mathrm{g} / \mathrm{ml}$ ) before exposed one time to $6 \mathrm{~h}$ of propofol $100 \mu \mathrm{M}$. After treatments, the TUNEL-positive neurons and the protein expression of $\mathrm{Cl}-\mathrm{Csp} 3$ were analyzed by TUNEL staining $(\mathbf{a})$ and western blots $(\mathbf{b})$, respectively. Densitometric analysis of $\mathrm{Cl}$-Csp3 protein was performed after normalization with $\beta$-actin (b). ${ }^{*} P<0.05$ vs Propofol group

propofol was dissolved in DMSO to exclude the potential impact of emulsion, equal volume of DMSO (the final concentration of DMSO was adjusted to $0.005 \%$ for each solution to avoid its possible nonspecific action) was added as the vehicle control in each treatment.

The clinically used tPA (Actilyse ${ }^{\circledR}$ ) is the approved drug for the acute treatment of ischemic stroke. Unfortunately, the narrow therapeutic window of tPA-induced thrombolysis and the risk of hemorrhage limited its use in clinical practice (Zhang et al. 2011; Saqqur et al. 2008). It also has been reported that tPA might endanger endothelial cells and neurons, resulting in an alteration of the integrity of components of the neurovascular unit (Yepes et al. 2009). In addition, intravenously administerd tPA can induce excitotoxic brain damage in rodents with intact or damaged blood-brain barrier (Benchenane et al. 2005; Lopez-Atalaya et al. 2007). However, the effects of tPA in reversing the neurotoxicity in developing neurons have not been reported in vivo and vitro. On the other hand, the involvement of $\mathrm{p} 75^{\mathrm{NTR}}$ in propofol-induced neurotoxicity has been demonstrated recently, which was verified by $\mathrm{p} 75^{\mathrm{NTR}}$ blockade and knockout (Pearn et al. 2012). Thus,we investgated the effects of propofol on the upstream signals of this pathway. Our data indicated that propofol reduced the amount of tPA present in culture media of developing hippocampal neurons. This reduction in TPA may be due to neuronal suppression by propofol, since tPA release from neurons is in an activity-dependent manner (Baranes et al. 1998; Lochner et al. 2008; Gualandris et al. 1996) and the well-known neuron activity depression effects of general anesthetics. After the inhibiting effects of propofol on tPA release in developing hippocampal neurons was verified, we further found that exogenous addition of tPA can partially reverse the propofol-induced neuron apoptosis.

In addition to direct plasminogen proteolytic function, tPA could also bind to the low density lipoprotein receptor expressed in neurons, which induces the ERK1/2 and Akt mediated antiapoptotic effects ( $\mathrm{Hu}$ et al. 2008; An et al. 2008). The urokinase-like plasmingoen activator receptor also can be binded by tPA and initiating the intracellular antiapoptotic signaling (Maupas-Schwalm et al. 2004). These findings may indicated that tPA addition not only making the mBDNF-mediated neuron growth promoting pathway dominant, but also initiating the anti-apoptotic effects by other pathways, which need to be elucidated in the future study. Another limitation of our study is that we did not investigate the effects of popofol or the different treatments on the growth of neonatal neurons, such as total number of dendrites, number of primary dendrites, and dendrite length. Moreover, the current study was performed in vitro, whether tPA administration also can attenuate apoptosis induced by propofol in developing neurons in vivo are the purpose of our further study.

\section{Conclusion}

Our study demostrated that propofol decreases tPA release in developing hippocampal neurons, and the addition of tPA could partially reverse the pro-apoptotic effect of propofol. Those findings may project new light on the basis of preventing the propofol-induced neurotoxicity in developing neurons.

\footnotetext{
Authors' contributions

The present study was designed and accomplished by CL, JC, and ZX. MD and FD were responsible for the research work flow. All authors read and approved the final manuscript.
}

\section{Acknowledgements}

This work was supported by the Natural Science Foundation of China (Grant No. 81400930), Youth Foundation of shanghai municipal commission of health and family (Grant No. 20144Y0234), Youth Foundation of zhongshang hospital 
(Grant No. 2014ZSQN27), and Excellent Youth project of zhongshang hospital (Grant No. 2015ZSYXQ N19).

\section{Competing interests}

The authors declare that they have no competing interests.

Received: 23 February 2016 Accepted: 2 April 2016

Published online: 18 April 2016

\section{References}

An J, Zhang C, Polavarapu R et al (2008) Tissue-type plasminogen activator and the low-density lipoprotein receptor-related protein induce Akt phosphorylation in the ischemic brain. Blood 112:2787-2794

Baranes D, Lederfein D, Huang YY et al (1998) Tissue plasminogen activator contributes to the late phase of LTP and to synaptic growth in the hippocampal mossy fiber pathway. Neuron 21:813-825

Benchenane K, Berezowski V, Ali C et al (2005) Tissue-type plasminogen activator crosses the intact blood-brain barrier by low-density lipoprotein receptor-related protein-mediated transcytosis. Circulation 111:2241-2249

Cattano D, Young C, Straiko MM et al (2008) Subanesthetic doses of propofol induce neuroapoptosis in the infant mouse brain. Anesth Analg 106:1712-1714

Chung HG, Myung SA, Son HS et al (2013) In vitro effect of clinical propofol concentrations on platelet aggregation. Artif Organs 37:E51-E55

Costela JL, Jimenez R, Calvo R et al (1996) Serum protein binding of propofol in patients with renal failure or hepatic cirrhosis. Acta Anaesthesiol Scand 40:741-745

Creeley C, Dikranian K, Dissen G et al (2013) Propofol-induced apoptosis of neurones and oligodendrocytes in fetal and neonatal rhesus macaque brain. Br J Anaesth 110(Suppl 1):i29-i38

Fredriksson A, Ponten E, Gordh T et al (2007) Neonatal exposure to a combination of $\mathrm{N}$-methyl-D-aspartate and gamma-aminobutyric acid type A receptor anesthetic agents potentiates apoptotic neurodegeneration and persistent behavioral deficits. Anesthesiology 107:427-436

Gualandris A, Jones TE, Strickland S et al (1996) Membrane depolarization induces calcium-dependent secretion of tissue plasminogen activator. J Neurosci 16:2220-2225

Head BP, Patel HH, Niesman IR et al (2009) Inhibition of p75 neurotrophin receptor attenuates isoflurane-mediated neuronal apoptosis in the neonatal central nervous system. Anesthesiology 110:813-825

Hu K, Lin L, Tan X et al (2008) tPA protects renal interstitial fibroblasts and myofibroblasts from apoptosis. J Am Soc Nephrol 19:503-514

Huettner JE, Baughman RW (1986) Primary culture of identified neurons from the visual cortex of postnatal rats. J Neurosci 6:3044-3060

Hume-Smith HV, Sanatani S, Lim J et al (2008) The effect of propofol concentration on dispersion of myocardial repolarization in children. Anesth Analg 107:806-810

Ikonomidou C, Bosch F, Miksa M et al (1999) Blockade of NMDA receptors and apoptotic neurodegeneration in the developing brain. Science 283:70-74

Jevtovic-Todorovic V, Hartman RE, Izumi Y et al (2003) Early exposure to common anesthetic agents causes widespread neurodegeneration in the developing rat brain and persistent learning deficits. J Neurosci 23:876-882

Keifer J, Sabirzhanov BE, Zheng Z et al (2009) Cleavage of proBDNF to BDNF by a tolloid-like metalloproteinase is required for acquisition of in vitro eyeblink classical conditioning. J Neurosci 29:14956-14964

Lee R, Kermani P, Teng KK et al (2001) Regulation of cell survival by secreted proneurotrophins. Science 294:1945-1948

Lemkuil BP, Head BP, Pearn ML et al (2011) Isoflurane neurotoxicity is mediated by p75NTR-RhoA activation and actin depolymerization. Anesthesiology 114:49-57

Li J, Xiong M, Alhashem HM et al (2014) Effects of prenatal propofol exposure on postnatal development in rats. Neurotoxicol Teratol 43:51-58

Liu F, Rainosek SW, Sadovova N et al (2014) Protective effect of acetyl-Lcarnitine on propofol-induced toxicity in embryonic neural stem cells. Neurotoxicology 42:49-57
Lochner JE, Spangler E, Chavarha M et al (2008) Efficient copackaging and cotransport yields postsynaptic colocalization of neuromodulators associated with synaptic plasticity. Dev Neurobiol 68:1243-1256

Lopez-Atalaya JP, Roussel BD, Ali C et al (2007) Recombinant Desmodus rotundus salivary plasminogen activator crosses the blood-brain barrier through a low-density lipoprotein receptor-related protein-dependent mechanism without exerting neurotoxic effects. Stroke 38:1036-1043

Lu B, Pang PT, Woo NH (2005) The yin and yang of neurotrophin action. Nat Rev Neurosci 6:603-614

Lu LX, Yon JH, Carter LB et al (2006) General anesthesia activates BDNFdependent neuroapoptosis in the developing rat brain. Apoptosis 11:1603-1615

Ludbrook GL, Visco E, Lam AM (2002) Propofol: relation between brain concentrations, electroencephalogram, middle cerebral artery blood flow velocity, and cerebral oxygen extraction during induction of anesthesia. Anesthesiology 97:1363-1370

Maupas-Schwalm F, Auge N, Robinet C et al (2004) The sphingomyelin/ceramide pathway is involved in ERK1/2 phosphorylation, cell proliferation, and UPAR overexpression induced by tissue-type plasminogen activator. FASEB J 18:1398-1400

Pearn ML, Hu Y, Niesman IR et al (2012) Propofol neurotoxicity is mediated by p75 neurotrophin receptor activation. Anesthesiology 116:352-361

Saqqur M, Tsivgoulis G, Molina CA et al (2008) Symptomatic intracerebral hemorrhage and recanalization after IV rt-PA: a multicenter study. Neurology 71:1304-1312

Twaroski DM, Yan Y, Olson JM et al (2014) Down-regulation of microRNA-21 is involved in the propofol-induced neurotoxicity observed in human stem cell-derived neurons. Anesthesiology 121:786-800

Varveris DA, Morton NS (2002) Target controlled infusion of propofol for induction and maintenance of anaesthesia using the paedfusor: an open pilot study. Paediatr Anaesth 12:589-593

Viviand X, Berdugo L, De La Noe CA et al (2003) Target concentration of propofol required to insert the laryngeal mask airway in children. Paediatr Anaesth 13:217-222

Vutskits L, Gascon E, Tassonyi E et al (2005) Clinically relevant concentrations of propofol but not midazolam alter in vitro dendritic development of isolated gamma-aminobutyric acid-positive interneurons. Anesthesiology 102:970-976

Xiong M, Li J, Alhashem HM et al (2014) Propofol exposure in pregnant rats induces neurotoxicity and persistent learning deficit in the offspring. Brain Sci 4:356-375

Yepes M, Roussel BD, Ali C et al (2009) Tissue-type plasminogen activator in the ischemic brain: more than a thrombolytic. Trends Neurosci 32:48-55

Yu D, Jiang Y, Gao J et al (2013) Repeated exposure to propofol potentiates neuroapoptosis and long-term behavioral deficits in neonatal rats. Neurosci Lett 534:41-46

Zhang B, Sun XJ, Ju CH (2011) Thrombolysis with alteplase 4.5-6 hours after acute ischemic stroke. Eur Neurol 65:170-174

\section{Submit your manuscript to a SpringerOpen ${ }^{\circ}$ journal and benefit from:}

- Convenient online submission

- Rigorous peer review

- Immediate publication on acceptance

- Open access: articles freely available online

- High visibility within the field

- Retaining the copyright to your article

Submit your next manuscript at springeropen.com 